Acta Hispanica (2020) Supplementum II: 177-187

\title{
ESTABLECIMIENTO DE RELACIONES DIPLOMÁTICAS ENTRE NICARAGUA Y HUNGRÍA
}

\author{
MÓNIKA SZENTE-VARGA \\ Universidad de Servicio Público, Budapest
}

Resumen: Este ensayo estudia los motivos y el contexto del establecimiento de los nexos diplomáticos húngaro-nicaragüenses y los primeros pasos de dichas relaciones en la primera mitad de la década de los 1980, en el período de la "pequeña guerra fría", con un enfoque sobre la apertura de las respectivas embajadas, las visitas oficiales y el auxilio húngaro enviado a Nicaragua. La motivación húngara fue primordialmente político-ideológica, estimulada tanto por las propias convicciones socialistas y los ideales de la solidaridad, como por la necesidad de ajustarse dentro del campo socialista y apoyar la política exterior soviética. El objetivo nicaragüense para estrechar los lazos con Hungría fue más bien económico, empujado por la necesidad de asegurar la supervivencia del sistema y sacar al país adelante.

Palabras clave: relaciones internacionales, historia interconectada, diplomacia, Guerra Fría, embajada.

\begin{abstract}
This essay studies the reasons and context of the establishment of diplomatic ties between Hungary and Nicaragua, and the first steps in these bilateral relations in the early 1980s, in the years of the "Little Cold War". Special emphasis is given to the opening of the respective embassies, official visits and Hungarian aid delivered to Nicaragua. The Hungarian motivation was primarily political and ideological, stimulated both by Socialist convictions and the ideals of solidarity and by the necessity of adjusting within the Socialist bloc and help the foreign policy of the Soviet Union. The goals of Nicaragua to intensify links with Hungary were more of economic nature, stemming from the necessity to secure the survival of the system and keep the country going.
\end{abstract}

Keywords: International Relations, Interconnected History, Diplomacy, Cold War, Embassy.

\section{Introducción}

Este ensayo se enfoca sobre el establecimiento de los nexos diplomáticos húngaronicaragüenses (1979) y los primeros pasos de dichas relaciones en la primera mitad de la década de los 1980, un período de la "pequeña guerra fría", cuando los vínculos entre los Estados Unidos y la Unión Soviética vinieron a menos. Por tanto, ganó importancia para este último país estrechar relaciones con estados como Cuba, Nicaragua, Etiopía, Angola y Zimbabwe, que formaron su "periferia imperial exterior" (Békés, 2012: 303). Debido al hecho de que la Unión Soviética tuvo que enfrentarse con crecientes problemas económicos y al mismo tiempo gastar un porcentaje muy elevado de su ingreso en armamentos, naturalmente se apoyó en los países socialistas europeos para mantener y fortalecer los nexos arriba mencionados. En los años ochenta Nicaragua figuró en un 
lugar destacado en las relaciones exteriores de Hungría.

Poco después de la victoria de la revolución sandinista, el primero de octubre de 1979, después de actos similares por parte de Cuba y Alemania del Este - pero antes que la Unión Soviética (!)-, Hungría y Nicaragua establecieron relaciones diplomáticas a nivel de embajadores ${ }^{1}$. Este entusiasmo inicial húngaro podría relacionarse con el júbilo por el cambio político en Nicaragua, y las relaciones de poder dentro del bloque socialista -es decir, quedar bien con la Unión Soviética al reaccionar rápido- y también con el hecho de que la apertura hacia dicho país centroamericano iba acorde con la política exterior húngara hacia América Latina en general. No obstante, ya en el siguiente paso, en la apertura de embajadas, se puede notar una disminución de tal entusiasmo.

Este ensayo estudia, desde un punto de vista húngaro, las razones detrás de este comportamiento ambiguo. Se basa por tanto en fuentes húngaras, principalmente en documentos de asuntos exteriores guardados en el Archivo Nacional de Hungría (Magyar Nemzeti Levéltár Országos Levéltára, MNL OL), complementados con la prensa de la época así como por los anuarios del Ministerio de Relaciones Exteriores.

\section{Contexto de las relaciones húngaro-latinoamericanas}

Los nexos entre Hungría y los países latinoamericanos quedaron rotos con la segunda guerra mundial. Después de la guerra, la política exterior húngara quiso y empezó a reconstruir las relaciones, lo que fue obstaculizado tanto por las realidades económicas como por la Guerra Fría y la división del mundo en dos bloques opuestos. El objetivo principal fue normalizar los lazos con los "tres grandes países", esto es, Argentina, Brasil y México. Sin embargo, hasta finales de la década de los 1950, solamente se habían (re)establecido relaciones diplomáticas con los siguientes países: Ecuador (1946), Argentina (1949), Bolivia (1952) y Uruguay (1956). La revolución húngara de 1956 y la subsiguiente intervención militar soviética bloqueó por varios años las posibilidades del gobierno Kádár para un acercamiento hacia América Latina. Incluso la Cuba revolucionaria dejó a Hungría en el último lugar entre los países socialistas en establecer relaciones, en 1960 (Horváth, 2018: 50-68). Los sesentas trajeron importantes cambios al lograr una normalización con Brasil (1961), y en la segunda mitad de la década con Chile (1965), Perú y Venezuela (1969), ya tras la amnistía en Hungría -aunque poco después de la intervención militar en Checoslovaquia-, en la que Hungría participó junto con otros países del Pacto de Varsovia. Siguieron Colombia en 1973 y México en 1974. Esta tendencia, (basada en gran parte en el mejoramiento de las relaciones húngaro-estadounidenses), y aunada al comportamiento de México, una potencia regional, pudo ejercer una influencia positiva sobre los países del

\footnotetext{
${ }^{1}$ Aunque estos nexos fueron presentados como nuevos, tuvieron sus antecedentes en el período de entreguerras, cuando las relaciones diplomáticas fueron establecidas entre Hungría y Nicaragua por primera vez. Hubo acreditación concurrente. La representación húngara en Washington cubrió también México, Cuba, Puerto Rico, Guatemala, El Salvador, Honduras, Nicaragua, Costa Rica y Panamá (Szente-Varga, 2017: 43).
} 
Caribe y América Central, donde se manifestó una avalancha diplomática. Los nexos bilaterales con Hungría fueron entonces (re)establecidos en los casos de Jamaica, Guayana, Trinidad y Tobago (1975), Granada y Surinam (1977) y Barbados (1978). Fue también este período, los setentas, cuando la política exterior húngara redescubrió a la América Central, empezando con Costa Rica (1970), seguido por Honduras (1973) y Panamá (1975). Añadir Nicaragua en 1979 cuadró perfectamente en el desarrollo arriba descrito (Magyar Külpolitikai Évkönyv, 1979: 263-277).

Para 1979 funcionaron siete embajadas húngaras en América Latina: una en México, otra en Cuba, y cinco en América del Sur (Argentina, Brasil, Colombia, Perú y Venezuela). Varias tenían concurrencias; por ejemplo, los países del Caribe se cubrían desde la representación húngara en Caracas, mientras los países del istmo centroamericano desde México. Por tanto, basándose en dicha práctica, al principio la política exterior húngara quiso cubrir Nicaragua también desde un tercer país. A finales de agosto de 1979, aún antes de establecer los nexos bilaterales, según el documento titulado Evaluación de condiciones en Nicaragua (Nicaragua 1979, caja 102, 111-1), la parte húngara planeó una acreditación concurrente desde un país cercano, aunque también se menciona en el mismo texto que Alemania del Este ya había abierto una representación in situ, lo que obviamente significó una cierta presión.

\section{Apertura de embajadas}

Debido a los deseos nicaragüenses, así como al comportamiento de los demás países socialistas y a la necesidad de ajustarse, Hungría al final abrió una embajada en Managua en julio de 1980. Al mismo tiempo Nicaragua cubría Hungría desde Moscú, contando el embajador, Dr. Ricardo Wheelock Román ${ }^{2}$ con una acreditación concurrente 3 . La razón tras este último arreglo fue la falta de recursos económicos.

Hubo frecuentes visitas bilaterales en 1981. Por la parte húngara, János Péter, vicepresidente del parlamento húngaro, visitó Nicaragua en marzo. Cuatro meses más tarde una delegación compuesta por miembros del Partido Socialista Obrero Húngaro (Magyar Sqocialista Munkáspárt, MSZMP) y del gobierno húngaro llegaron para participar en los

${ }^{2}$ Coronel, jefe de la inteligencia militar del ejército popular sandinista. Ocupó diversos cargos diplomáticos y fue director del Instituto de Historia del Ejército de Nicaragua. Falleció en 2018. Hermano del comandante Jaime Wheelock Román (1946-), ministro de agricultura del gobierno sandinista ("Recuerdan a Ricardo Wheelock R.", 24-06-2019).

${ }^{3}$ Parece que al principio no estuvo tan claro desde donde organizarían la representación concurrente, o es también posible que las informaciones húngaras estén equivocadas. Hay un documento sobre la visita de Ricardo Wheelock a Budapest en mayo de 1981,-según el cual Wheelock confirmó que Joaquín (sic) Centeno había sido nombrado embajador de Nicaragua en Hungría y se desempeñaría en su cargo con sede en Praga. Añadió que pronto abrirían una embajada en Budapest, donde la hija de Centeno podría trabajar como encargada de negocios (MNL OL. Nicaragua, 1982, caja 77, 111-17). 
eventos conmemorativos del segundo aniversario del derrocamiento de la dictadura de Somoza y del 20 aniversario de la fundación del Frente Sandinista de Liberación Nacional, y al final del año, en noviembre, el ministro de relaciones exteriores, Frigyes Puja, viajó en visita oficial a Nicaragua. Las visitas nicaragüenses a Hungría fueron aún más frecuentes e incluyeron la llegada a Hungría del comandante Carlos Núñez Pérez, presidente de la Asamblea Nacional, con una delegación en abril, seguida por el ministro de relaciones exteriores, Miguel d'Escoto Brockman, en junio; y el fundador del FSLN y ministro de interior, Tomás Borge, en agosto, así como por las del ministro de industria, Enrique Baltodano, del secretario general del Partido Socialista de Nicaragua, Gustavo Tablada, y del ministro de educación, Carlos Tünnermann Bernheim, las tres en septiembre (Magyar Külpolitikai Évkönyv, 1981: 12-43).

Estos encuentros sirvieron entre otros fines para estrechar lazos, mostrar una buena imagen de Hungría y del mundo socialista en general y promover los intereses de Nicaragua, entre ellos la apertura de una embajada en Budapest. También hubo peticiones nicaragüenses dirigidas a la embajada húngara en Managua en el mismo sentido, y el embajador de la República de Nicaragua en Checoslovaquia, con sede en Praga, Dr. Achilles Centeno Pérez ${ }^{4}$, de visita en Hungría entre el 30 de diciembre de 1981 y el 5 de enero de 1982, también planteó el asunto, como un encargo por parte de Daniel Ortega y Miguel d'Escoto Brockman (MNL OL. Nicaragua, 1982, caja 77, 111-17).

Tanto las insistencias nicaragüenses, en particular desde la segunda mitad de 1981, como la apertura de las embajadas de dicho estado centroamericano en los demás países socialistas, forzaron al liderazgo político húngaro a actuar. El Ministerio de Relaciones Exteriores de Hungría pidió por una parte la opinión de su Departamento de Finanzas, así como reportes de las representaciones húngaras en Moscú, Berlín, Praga y Sofía sobre el apoyo que gozan las embajadas nicaragüenses en dichas ciudades.

Al respecto, el Departamento de Finanzas insistió en que tal acción sobrepasa el presupuesto del Ministerio y solamente se puede llevar a cabo a nivel estatal. En cuanto a las consultas requeridas a las representaciones húngaras en Moscú y otras capitales socialistas $^{5}$, la información obtenida se podría resumir de la siguiente manera:

La Unión Soviética compró un solar en Managua donde erigirá su embajada. En Moscú le concedió gratis un terreno a Nicaragua para construir el edificio de su representación. Mientras los edificios no estén listos, las dos partes proveen al otro con oficinas y viviendas sin la necesidad de pagar renta. A los diplomáticos nicaragüenses la Unión Soviética facilitó un préstamo sin intereses por dos años para la compra de muebles, aparatos de oficina, coche, ropa caliente. Les procura también asistencia médica.

El gobierno nicaragüense proporcionó el edificio de la embajada y las casas de los diplomáticos búlgaros en Managua de manera gratuita y, con base en la reciprocidad, Bulgaria cubre estos gastos en Sofía. Los búlgaros dan 30,000 levas cada seis meses para

\footnotetext{
${ }^{4}$ Entonces juez de la Suprema Corte, estuvo bajo tratamiento médico en Hungría en 1980 por 8 meses. Falleció en 1990.

${ }^{5}$ No llegó información correspondiente desde Alemania del Este.
} 
el funcionamiento de la embajada de Nicaragua en Bulgaria, y cubren los sueldos de los empleados locales (un chófer, dos intérpretes y una encargada de limpieza).

El gobierno checoslovaco, gracias a una decisión gubernamental, proveyó los edificios de la embajada y la residencia, así como las viviendas de los diplomáticos nicaragüenses. Pagan por todo 500 dólares mensuales. Antes de moverse a los inmuebles, los gastos de hotel de los diplomáticos fueron pagados por la parte checoslovaca, similarmente como lo hizo la Unión Soviética con los representantes nicaragüenses que llegaron a Moscú.

Finalmente, el 16 de febrero de 1982 el Ministerio de Relaciones Exteriores de Hungría preparó una propuesta para el Buro Político que entre otros puntos dice: "Recomendamos que de conformidad con la petición nicaragüense, se asignen fondos financieros para el establecimiento de la embajada de Nicaragua en Budapest, así como para su funcionamiento hasta finales de 1984. Los gastos aproximados serían alrededor de 10 millones de forintos. La embajada comenzará a funcionar en la segunda mitad de este año.” (MNL OL. Nicaragua, 1982, caja 77, 111-17).

En efecto, la embajada de Nicaragua en Budapest ya figura en 1982 en el anuario del Ministerio de Relaciones Exteriores de Hungría ${ }^{6}$. La primera representante nicaragüense en Budapest fue la embajadora Eva Conrado Flores.

\section{Condiciones económicas y apoyo financiero}

El motivo principal para abrir la embajada en Budapest fue tratar de facilitar ayuda económica para Nicaragua. En 1979 cuando los sandinistas llegaron al poder, el PIB cayó 26.5\%. Los años 1980, 1981 y 1983 trajeron consigo un crecimiento que sobrepasó el 4\%, pero en 1982 (cuando la representación nicaragüense abrió sus puertas en la capital húngara) así como de 1984 a 1991 la economía iba contrayéndose (Countryeconomy, Nicaragua, 24-06-2019).

\footnotetext{
${ }^{6}$ En el mismo volumen la embajada de Hungría en Managua ya figura con dos concurrencias, Costa Rica y Panamá, con toda seguridad para bajar la carga de trabajo de la representación húngara en la Ciudad de México, que se había encargado de dichos países en el pasado.
} 
Establecimiento de relaciones diplomáticas entre Nicaragua y Hungría

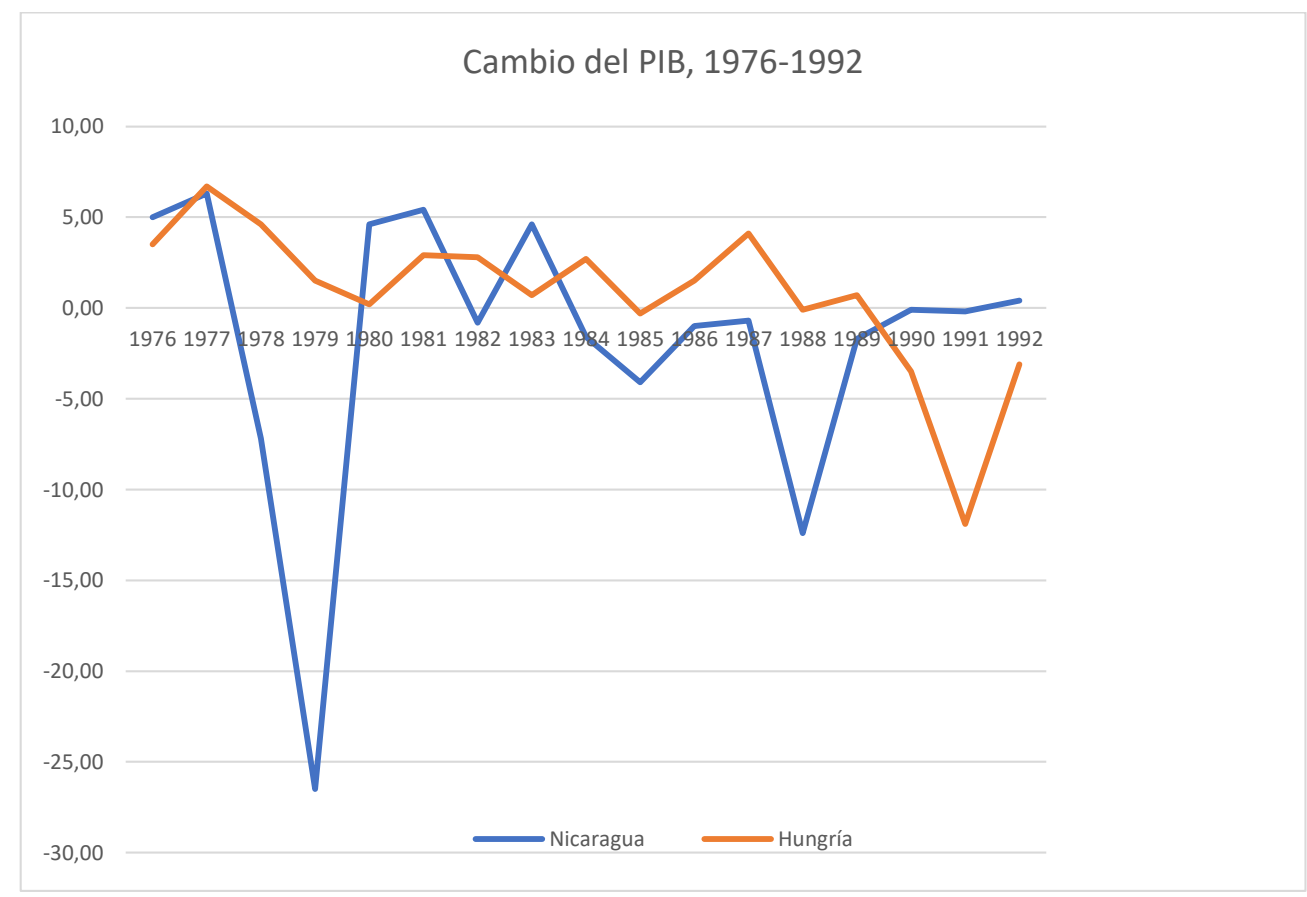

(Fuente: Countryeconomy. Nicaragua; Hungary, 24-06-2019)

En el año de la victoria sandinista el PIB total de Hungría fue unas doce veces más que el PIB nicaragüense, mientras la diferencia entre la población de ambos países resultó ser mucho menor, con unos 3,2 millones de personas viviendo en el país centroamericano y 10,7 en Hungría (3,3 veces más). La esperanza de vida en Hungría era entonces de 69,6 años y en Nicaragua 58,1 años (Worldbank, 24-06-2019). El liderazgo nicaragüense confiaba obtener apoyo (financiero, técnico, etc.) de Hungría y de los demás países socialistas. No obstante, el crecimiento económico de Hungría había perdido su ímpetu; su promedio anual fue de 2,9\% en el período de 1976-1980 y solamente 1,6\% entre 1981 y 1985 (Romsics, 1999: 448). Al mismo tiempo creció la deuda exterior. El liderazgo nicaragüense posiblemente no conocía a fondo las verdaderas condiciones y los problemas de la economía húngara, y además, tal vez en parte como resultado de las visitas realizadas, tenía una imagen demasiado positiva de Hungría. Por tanto la ayuda financiera húngara no llegó a alcanzar las expectativas nicaragüenses. Las cifras reflejan un crecimiento: 2,7 millones de forintos en 1981; 8,9 millones en 1982; 24,3 millones en 1983 y 148,2 millones en 1984, pero en total la ayuda no sobrepasó los 190 millones de forintos en dicho período (MNL OL. Nicaragua 1984, caja 85, 111-51). 
Ayuda húngara a Nicaragua (1981-84) en millones de forintos:

1981

\begin{tabular}{|l|l|}
\hline Apoyo civil, libre de retribución & 0,9 \\
\hline -Comité de Solidaridad & $(0,34)$ \\
-Cruz Roja & $(0,56)$ \\
\hline Cooperación tecnológica y científica & 0,79 \\
\hline Ministerio de Cultura & 1,01 \\
\hline Total & $\mathbf{2 , 7}$ \\
\hline
\end{tabular}

1982

\begin{tabular}{|l|l|}
\hline Apoyo civil, libre de retribución & 3,0 \\
\hline -Fondo de auxilio de asuntos exteriores & $(2,2)$ \\
-Comité de Solidaridad & $(0,8)$ \\
\hline Cooperación tecnológica y científica & 4,23 \\
\hline Ministerio de Cultura & 1,72 \\
\hline Ministerio de Salud & 0,05 \\
\hline Total & $\mathbf{8 , 9}$ \\
\hline
\end{tabular}

1983

\begin{tabular}{|l|l|}
\hline Apoyo civil, libre de retribución & 6,8 \\
-Fondo de auxilio de asuntos exteriores & 3,5 \\
\hline -Comité de Solidaridad & 3,3 \\
\hline Cooperación tecnológica y científica & 7,3 \\
\hline Ministerio de Cultura & 2,1 \\
\hline Ministerio de Salud & 0,35 \\
\hline Auxilio militar & 7,8 \\
\hline Comité Central de la Juventud Comunista (KISZ) & 0,02 \\
\hline Total & $\mathbf{2 4 , 3}$ \\
\hline
\end{tabular}

1984

Apoyo civil, libre de retribución

-Comité de Solidaridad

0,61

0,16

Acta Hispanica, Hungría, Supplementum II: 177-187, 2020, ISSN: 1416-7263 |183 
Establecimiento de relaciones diplomáticas entre Nicaragua y Hungría

\begin{tabular}{|l|l|}
\hline -Cruz Roja & 0,45 \\
\hline Cooperación tecnológica y científica & 8,2 \\
Auxilio militar & 43,9 \\
\hline Auxilio - víveres /Terimpex, Monimpex/ & 79,0 \\
\hline Auxilio - medicamentos /Medimpex/ & 1,8 \\
\hline Auxilio - papel /Lignimpex/ & 14,5 \\
\hline Total & $\mathbf{1 4 8 , 2}$ \\
\hline
\end{tabular}

Llama la atención, que desde 1983 la ayuda incluyó auxilio militar, que en ese año formó la tercera parte de todo el apoyo financiero, y en 1984 fue la segunda en cuanto al monto, tras los víveres, igualmente con alrededor del 30\% del total de la asistencia. Sin embargo, mientras las proporciones no cambiaron mucho, las cantidades sí: de 7,8 millones a 43,9 millones, un crecimiento de más de 5 veces en 12 meses (MNL OL. Nicaragua 1984, caja 85, 111-51).

No fue la capacidad económica húngara que motivó el aumento espectacular en la ayuda total -que creció más de 50 veces en tres años- sino las condiciones precarias en Nicaragua, tanto en el campo económico como en el militar. En su reporte anual, János Kiss, embajador de Hungría en Managua, anota lo siguiente:

La situación actual del sistema sandinista es sumamente adversa. [...] El destino de la revolución nicaragüense puede ser influenciado en gran medida por las condiciones internacionales, entre ellas el desarrollo del nexo soviético-estadounidense. Desempeña un papel principal la ayuda política y económica de los países socialistas, de la cual depende no solamente la supervivencia de la revolución, sino también su desarrollo o posible desviación (MNL OL. Nicaragua 1985, caja 113, 111-142; Szente-Varga, 2018: 81-82).

Hay que añadir, que en este esfuerzo común, Hungría tuvo un rol menor. La Unión Soviética, Cuba, Alemania del Este y Bulgaria fueron más activos.

\section{Conclusiones}

Nicaragua apareció en el radar político húngaro cuando los mejores años para la economía húngara ya eran cosa del pasado y cuando el liderazgo de los países socialistas ya había adquirido una experiencia no completamente satisfactoria en cuanto a Cuba (Bortlová Vondráková, 2011; Szente-Varga, 2005). No obstante, los lazos con Cuba trajeron un acercamiento tanto con la isla como con América Latina en general, y los nexos con Nicaragua llevaron consigo un creciente número de contactos con el istmo centroamericano, una región ignorada por varias décadas tras la segunda guerra mundial 
por la política exterior húngara. Este estudio analizó las circunstancias del (re)establecimiento de los vínculos diplomáticos entre Nicaragua y Hungría en 1979, y el desarrollo de la cooperación en los primeros años de la década de los ochenta. El objetivo nicaragüense para estrechar los lazos con Hungría fue más bien económico, empujado por la necesidad de asegurar la supervivencia del sistema y sacar al país adelante. La motivación húngara fue primordialmente político-ideológica, estimulada tanto por las propias convicciones socialistas y los ideales de la solidaridad, como por la necesidad de ajustarse dentro del campo socialista.

En el material archivístico abundan las comparaciones con otros países socialistas. Esto por una parte sirvió como información, pero por la otra, también como presión. La referencia más importante fue la Unión Soviética, naturalmente. "Los diplomáticos soviéticos recalcaron en las conversaciones que sostuvieron con nosotros que la situación y el desarrollo en Nicaragua únicamente se pueden valorar y planear tomando en cuenta las interrelaciones políticas internacionales en un contexto global” (MNL OL. Nicaragua 1979, caja 102, 111-1, 00984/12). En cuanto a la relación húngaro-soviética, vale la pena recurrir a un documento más tardío, de octubre de 1988, que abiertamente se trata de una solicitud soviética. Mientras en la mayor parte de la década de los 80 el liderazgo húngaro no hubiera dudado en satisfacer una demanda soviética, la situación cambió para los últimos años del período. La petición de la Unión Soviética de dar 20 mil toneladas de petróleo crudo a Nicaragua en 1989 y en 1990 en forma de ayuda, fue rechazada por el gobierno húngaro, alegando dificultades económicas. No obstante, cuando la parte soviética repitió la solicitud, el Buro Político tomó la siguiente decisión, el 13 de diciembre de 1988: Hungría mandaría 10 mil toneladas de petróleo a Nicaragua tanto en 1989 como en 1990. Sin embargo, al parecer, debido a los cambios políticos, dichos envíos ya no se efectuaron (MNL OL. Nicaragua 1989, caja 89, 111-5). ${ }^{7}$

Para terminar, valdría la pena echar un vistazo, aunque sea superficial, justamente a la segunda mitad de los años ochenta, cuando con la llegada al poder de Mijaíl Gorbachov empezaron las reformas internas en la Unión Soviética y también en algunos países socialistas, así como un cierto aflojamiento de los países satélites debido a los problemas económicos soviéticos. La era de Gorbachov puso fin a la llamada pequeña guerra fría, sin embargo la situación en Nicaragua fue de mal en peor; en 1988 el país sufrió una caída del PIB de 12,4\%. Y después vino 1989, el llamado año de los milagros en Europa Central y Oriental, el principio de la transición política.

En 1990 hubo elecciones tanto en Hungría como en Nicaragua. En Hungría éstas pusieron fin a la época socialista, mientras en Nicaragua significaron el fin del régimen sandinista. Tanto Nicaragua como Hungría cambiaron su posición en la gran tabla de ajedrez de las relaciones internacionales cuando terminó la Guerra Fría, lo que resultó en un alejamiento y convirtió las intensas relaciones de la década de los ochenta en otro

\footnotetext{
${ }^{7}$ Hungría envió 30 mil toneladas de petróleo crudo en 1985, 50 mil toneladas en 1986, y 10 mil toneladas tanto en 1987 como en 1988.
} 
Establecimiento de relaciones diplomáticas entre Nicaragua y Hungría

episodio, en el que, sin embargo, vale la pena ahondar, para aprender más sobre la historia de los propios países, así como sobre la lógica y los mecanismos del mundo bipolar.

\section{Referencias de archivo}

MNL OL. k IV Nicaragua 1989, caja 89, 111-5 Térítésmentes olajszállitás Nicaraguának [Suministro de petróleo para Nicaragua, de manera gratuita].

MNL OL. j IV Nicaragua 1985, caja 113, 111-142 Az 1985. évi nagyköveti beszámoló jelentés [Reporte anual del embajador, 1985].

MNL OL. k IV Nicaragua 1984, caja 85, 111-51 A Magyar-nicaraguai gazdasági együttmüködés kialakításának feltételei [Condiciones para la cooperación económica entre Hungría y Nicaragua].

MNL OL. k IV Nicaragua 1982, caja 77, 111-17 Nicaraguai segítségkérés budapesti nagykövetségük felállításához [Petición de ayuda por parte de Nicaragua para el establecimiento de su embajada en Budapest].

MNL OL. j IV Nicaragua 1979, caja 102, 111-1 Diplomáciai kapcsolat felvétele Nicaraguával [Establecimiento de relaciones diplomáticas con Nicaragua].

\section{Referencias bibliográficas}

Békés, Csaba (2012). Magyarország, a szovjet bloke és a nemzetközi politika az enybülés idôszakában 1953-1991. Budapest: disertación académica.

Bortlová Vondráková, Hana (2011). Ceskoslovensko a Kuba v letech 1959-1962. Praga: Universidad Carolina de Praga.

Countryeconomy. Nicaragua GDP. Asequible en: https://countryeconomy.com/gdp / nicaragua?year=2009, fecha de consulta: 24-06-2019.

Countryeconomy. Hungary GDP, Asequible en: https://countryeconomy.com/gdp / hungary?year=2009, fecha de consulta: 24-06-2019.

Dömény, János (2009). Magyar diplomata Latin-Amerikában. Szeged: [s.n.].

Horváth, Emőke (2018). A magyar-kubai diplomáciai kapcsolatok létrejöttének sajátos fordulatai. Aetas, 33. 1. 50-68.

Magyar Külpolitikai Évkönyv. (1979-1981). Budapest: Külügyminisztérium.

Recuerdan a Ricardo Wheelock R. El Nuevo Diario, 6 de marzo de 2018. Asequible en: https:/ /www.elnuevodiario.com.ni/nacionales/457665-recuerdan-ricardo-wheelock-r/, fecha de consulta: 24-06-2019.

Romsics, Ignác (1999). Magyarország története a XX. sqázadban. Budapest: Osiris. 
Szente-Varga, Mónika (2018). Relaciones húngaro-nicaragüenses en la década de los 1980. En: Alcántara, Manuel - García Montero, Mercedes - Sánchez López, Francisco (eds.). Relaciones internacionales: $56^{\circ}$ Congreso Internacional de Americanistas. Salamanca: Universidad de Salamanca. 78-86.

Szente-Varga, Mónika (2017). El baúl de las nomeolvides. Relaciones húngaro-mexicanas. Budapest: Dialóg Campus.

Szente-Varga, Mónika (2005). El lugar de Cuba en el mundo político. Opiniones checoslovacas desde La Habana. En: Opatrný, Josef (ed.). Nación y cultura nacional en el Caribe hispano. Praga: Universidad Carolina de Praga. 357-367.

Worldbank. Data for Hungary, Nicaragua. Asequible en: https://data.worldbank.org/ ?locations=HU-NI, fecha de consulta: 24-06-2019. 